\title{
Lung cancer in workers in a nickel refinery
}

\author{
L. KREYBERG
}

From the Institute of Pathology, University of Oslo, Rikshospitalet, Oslo 1, Norway

ABSTRACT This study is an analysis of the occurrence of lung cancer in nickel workers, particularly with regard to development time, histological types and tobacco smoking, in addition to specific exposure to nickel dust and fumes. It is a continuation of previous work in this field (Kreyberg, $1954 \mathrm{a}, \mathrm{b} ; 1962,1969)$. The series consists of 44 cases of lung cancer occurring during the years 1948-74 in people currently or previously employed at Falconbridge nickel refinery. A seven-year period of reduced activity during the war enables lung cancer in workers who took up employment in 1927-39 to be compared with that in workers who started in or after 1946. It is confirmed that exposure to nickel dust and fumes increases the risk of developing lung cancer. However, all subjects with small cell anaplastic carcinoma and at least 25 out of 28 subjects with epidermoid carcinoma had been tobacco smokers. Four smokers and four non-smokers had Group II tumours. The mean age at diagnosis of lung cancer in the nickel workers corresponds closely with that of male subjects with lung cancer in general, in spite of the very wide differences in the development time, if this is related to the employment time in the refinery alone. The mean age at diagnosis is, however, consistent if the development time is related to the length of tobacco smoking. Tobacco smoking is an important factor in the development of lung cancer in nickel workers, and under the conditions described in this study the reduced carcinogenic influence may be attributable to reduced exposure to nickel and possibly also to tobacco.

In Norway Løken (1950), who had searched unsuccessfully for earlier cases of lung cancer in the nickel refinery, described the three first cases of epidermoid lung cancer in workers at the Falconbridge Nikkelverk A/S nickel refinery near Kristiansand, southern Norway. In the same year another two cases of epidermoid lung carcinoma were found. These five cases would probably not have been associated with the specific occupation if we had not just started a systematic study of lung cancer at our Institute.

These cases caused some consternation at the refinery and the health authorities were duly informed. But then unexpectedly during the years 1952-7 inclusive only a single case of lung cancer (without histological confirmation) was reported from the refinery, and the whole problem receded although we kept in regular contact with the factory doctor. The absence of new cases was therefore not a result of neglect. In 1958 two new cases were found and in the following year another two, all epidermoid carcinomas; since then lung cancer has regularly been observed at Falconbridge.

Received for publication 29 March 1977

Accepted for publication 7 June 1977
Pedersen et al. (1973) reviewed lung cancer at Falconbridge, using conventional statistical techniques, and concluded that during the period 1953-71 there were 48 cases of lung cancer. The highest risk was among the men involved in roasting, smelting and electrolysis.

In 1948-50 the frequency of lung cancer in Norway was beginning to change, although this was not generally recognised. The initial increase in the mortality statistics was probably a result of improved diagnosis. But gradually the increase was accompanied by other changes: an increasing male/ female ratio and an increasing urban/rural ratio. During the following years Kreyberg (1954a, b; 1962, 1969) observed and underlined another increasing ratio, Group I (epidermoid and small cell anaplastic carcinoma)/ Group II tumours (adenocarcinomas and the other histological types). He pointed out that Group I tumours predominated in cases in which ionising radiation, arsenic, chromium, or tobacco smoking played a part, whereas adenocarcinomas and the other types were few. Since then it has been generally accepted that the enormous rise in lung cancer, predominantly Group I tumours, was caused by tobacco, especially cigarette smoking.

The conventional observation is that the incidence 
of cancer increases and the development time decreases when the dose of carcinogen is increased. But in lung cancer associated with tobacco smoking, in spite of a clear linear increase in the incidence with the dose, the mean age at tumour appearance is nearly constant. Nevertheless, H. J. A. Kreyberg (1965) demonstrated that these seemingly irreconcilable findings were those to be expected of weak carcinogens. In addition, Kreyberg (1967) showed, by a very strict differentiation of the histological types and precise recording of the amount smoked, that the age factor was, in fact, influenced. If smoking methods are considered, clear differences in occurrence are observable, as shown in Fig. 1.

OCCUPATION, SMOKING AND LUNG CANCER The problem was studied in a fairly large Norwegian series (Kreyberg, 1969), in which it was shown that in some trades and occupations individuals tend to smoke heavily and that some trades and occupations are connected with social habits and traditions that particularly favour cigarette smoking. This means that the tobacco consumption itself is occupationally influenced to a certain degree. The risk of developing lung cancer is determined by the method and the amount of smoking rather than by the trade or occupation per se. Workers in some occupations with the same smoking pattern, or even a lower tobacco consumption, such as furniture makers,

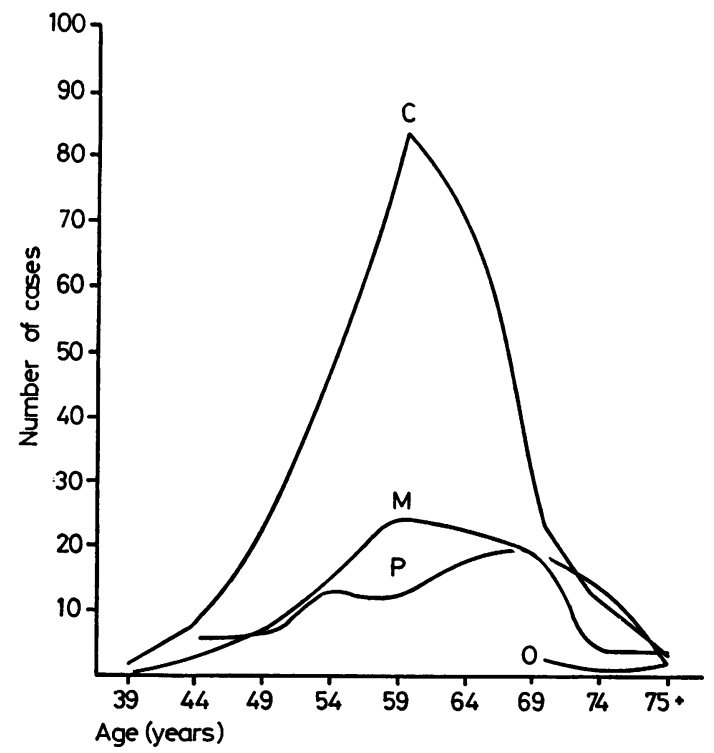

Fig. 1 Smoking habits of control subjects (Kreyberg) and age at diagnosis of epidermoid carcinomas. $C=$ cigarette; $M=$ cigarette and pipe; $P=$ pipe; $O=$ non-smoker. masons, painters and metal workers, are at higher risk. The nickel workers belong to the latter category.

\section{Present investigation}

Our series consists of 44 cases of lung cancer occurring during the years 1948-74 in persons currently or previously employed at the Falconbridge nickel refinery. All have been followed up, and most of the cases have already been analysed (Pedersen et al., 1973), but we also include the original five cases (1948-50) as well as four additional cases, two from 1972 and two from 1974. On the other hand, we rejected 13 cases because adequate material for histological typing was not available. This does not affect the quality of the material, but reduces the number. In fact, only one case (from 1953) occurring before 1958 had to be omitted (marked in the figures by ?). Two other cases from 1951, with 12 months and 2 months of development time, respectively, will only be included in certain connections. They cannot reasonably be connected with nickel exposure, and are not included in Fig. 2, which shows the types of tumour and their year of diagnosis. This Figure also shows the population of the Falconbridge nickel refinery, divided into permanent staff (B) and permanent plus temporary workers (A). The ' $a$ ' curves represent the total population on the payroll. The difference between the ' $a$ ' and ' $b$ ' curves represents administrative staff not regularly exposed to nickel dust and fumes.

The factory started refining in 1927 on a modest scale which increased until an abrupt reduction occurred when the Germans invaded Norway in 1940. The number of workers employed did not reach its pre-war level again for about eight years. Some of the original staff continued to work during the war years (1940-5) but others never returned. From 1946 onwards new workers were engaged in steadily increasing numbers.

Nickel production, 9121 tonnes a year in 1939, was reduced to 3732 tonnes in 1940 and was lowest in 1943 with 872 tonnes. Production again reached 8000 tonnes in 1947. This means that the curve for the production of nickel closely followed the curve of workers employed (Fig. 2).

These events represent an unintentional experiment in human carcinogenesis. The workers employed between 1927 and 1939 lived under economic and social conditions differing considerably from those of the workers employed in 1946 and later. During the years $1940-5$ very few new workers were engaged. We therefore divided the workers into Series I, those whose employment began in the years 1927-39, and Series II, the workers whose employment began in 1946 or later. 


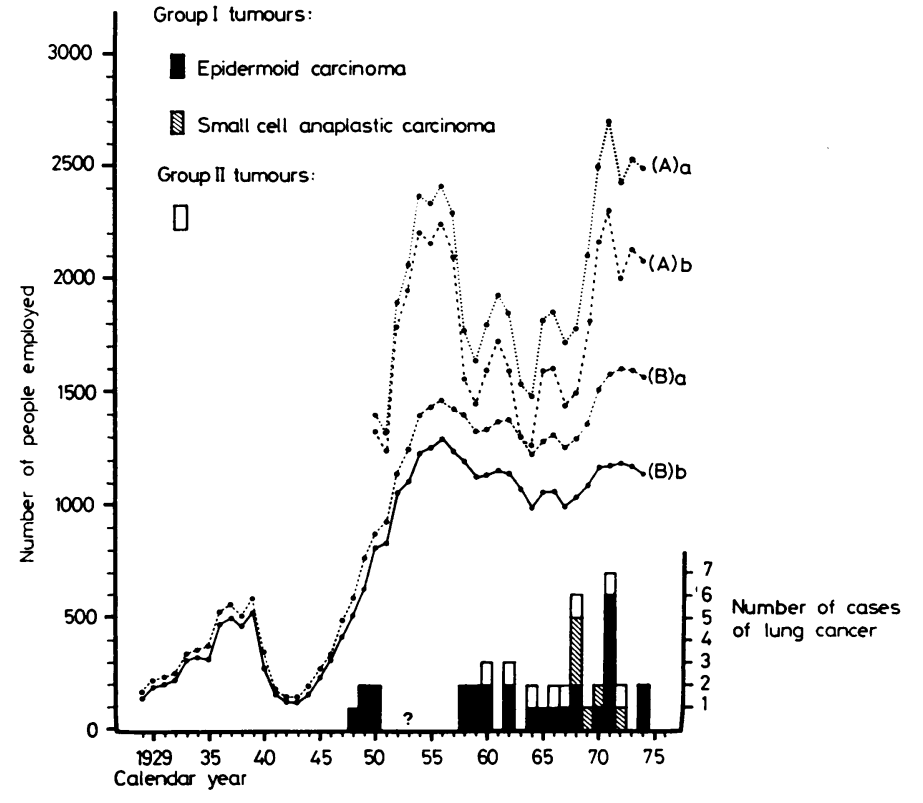

Fig. 2 Number of people employed at Falconbridge nickel refinery (curves) and number of new cases of lung cancer diagnosed between 1929 and 1975 (histogram). $A=$ number of people on the payroll $(a=$ total number, $b=$ those occupationally exposed to nickel); $B=$ number of people in established positions ( $a=$ total number, $b=$ those occupationally exposed to nickel). The two cases from 1951 with development time of 1 year or less are not included.
TOBACCO CONSUMPTION

In 41 out of the 44 cases this is known from the hospital records or from patients' statements noted by laboratory staff. Some of the information is complete with notes on smoking methods and amounts of tobacco smoked. In others the statements are less complete, such as 'smoked since the age of six years', and 'heavy smoker'. Only the first three cases (19489) are without documentary information, but a few years ago an old foreman at the refinery declared that the three persons in question were 'non-drinkers and non-smokers'. We cannot definitely accept nor ignore this information some 25 years after the death of the workers, inasmuch as several cancer victims, stated to be non-smokers, were later shown to be smokers, even heavy smokers, after careful perusal of the hospital archives.

During the eight-year period of reduced staff and reduced activity at the refinery, the general availability of tobacco was also reduced.

\section{EXPOSURE TO NICKEL}

The degree and the length of exposure to nickel will not be discussed in any detail, not least because we do not know which form of nickel is the active carcinogen. If nickel acts in its metallic state or in stable compounds, the specific carcinogen may continue to act many years after the last exposure to it. In fact, in our case No. 7 (Case 3 in Løken (1950)) the lung tissue, surgically removed 10 years after the patient had left Falconbridge, contained 2.8 mg nickel per gram dry substance. If, on the other hand, the carcinogenic compound is more or less unstable and/or rapidly excreted when the employment and direct exposure terminates, there may be a stopped exposure effect as described by Doll (1964) for tobacco smokers giving up smoking. In addition, the individual exposure may vary according to site of work, personal habits and precautions taken.

\section{TIME FACTORS}

Another feature which is measurable is the development time of the tumours, if this is defined as the time from taking up employment to the moment of clinical cancer diagnosis, regardless of possible interruptions of the work, or termination of the employment. Time of latency will in this paper mean the time from the termination of employment to the time of cancer diagnosis.

In the following analysis, all our cases of lung cancer observed at Falconbridge will initially be assumed to be caused by nickel. Only later will other factors inherent in the series be introduced as controls or as correctives for the final conclusions. On the other hand there are a few caveats to be mentioned. First, two cases from Series II; a commercial traveller, aged 65 at diagnosis in 1958, after four years' employment and suffering from an epidermoid carcinoma; and an office messenger, aged 60 at diagnosis in 1962, after eight years' employment, suffering from an adenocarcinoma; neither of whom had been exposed to nickel in their work: secondly, 
Table 1 Development of tumours in Series I workers

\begin{tabular}{llll}
\hline Series I workers* & \multicolumn{2}{l}{ Tumour development time (years) } & Maximum \\
\cline { 2 - 4 } & Mean & Minimum & \\
\hline The first 5 cases & 20 & 17 & 22 \\
$\quad$ Epidermoid carcinoma & 20 & - & - \\
The subsequent 13 cases & $34 \cdot 6$ & 31 & 30 \\
$\quad$ Case no. 14; epidermoid carcinoma & 35 & 34 & 36 \\
Epidermoid carcinoma (8) & 34 & 31 & 37 \\
Small cell anaplastic carcinoma (2) & & & \\
Group II tumour (2) & & & \\
\hline
\end{tabular}

*One office clerk with epidermoid cancer is not included in Tables 3, 4 and 5.

in certain connections attention will be concentrated on the Group I tumours only, as explained below.

Possibly the most striking feature of Fig. 2 is the two depressions of the curves, the first marking the reduction in number of workers employed, as well as the reduced activity of the refinery over a period of some eight years, as already mentioned; the other marking the interval in which lung cancer diagnoses were lacking: a gap of seven years (six years if the two cases with an employment time of one year or less are counted). In the series cited by Pedersen et al. (1973) there is also the single case from 1953, not histologically verified. All their other cases occur after the gap.

The simplest explanation would be to relate the two depressions and assume that the first five cases were manifestations from the workers of Series I and that the later cases belong to Series II. If this correlation were a biological reality, it would point to a shortest development time of about 10 years, 1939-48 and 1946-58, respectively. However, this does not stand up to closer examination. The first five cases belong to Series I, but no less than 13 of the 37 (39) later cases also belong to Series I, some workers being employed right from the time the refinery started in 1927. This means that these 13 cases with their lung cancer in a preclinical stage bridge the eight-year gap without lung cancer diagnoses in Series I (except the single case from the series of Pedersen et al. (1973)).

\section{Series I}

Series I shows a remarkable picture. As the workers taken on between 1927 and 1939 have now been observed for between 35 and 47 years after starting their employment at a mean age of 28.6 years, and as most of them have now died, no more data which can alter the picture can be expected.

The development times of the tumours in Series I are shown in Table 1. For the first five cases the shortest development time was 17 years (a single case) and the other four cases had development times of 20-22 years. Among the later 13 cases, there is a single one with a development time as short as 20 years, whereas the remaining 12 cases took much longer to develop, from 31 to 40 years. This reveals a new gap, a break of eight years (23 to 31 years) in which no tumour appeared. It is the prolongation of the development time which causes this gap of eight years, and it explains the gap in the chronological appearance, recorded above as secondary.

The relationship between the two gaps is illustrated in Fig. 3, where all the tumours have been plotted in relation to start of employment and year of tumour diagnosis. The period of reduced activities is likewise indicated. It may be objected that the gap described is a result of the relatively small number of cases. In an orderly conducted animal experiment with a sufficient number of individuals, the cumula-

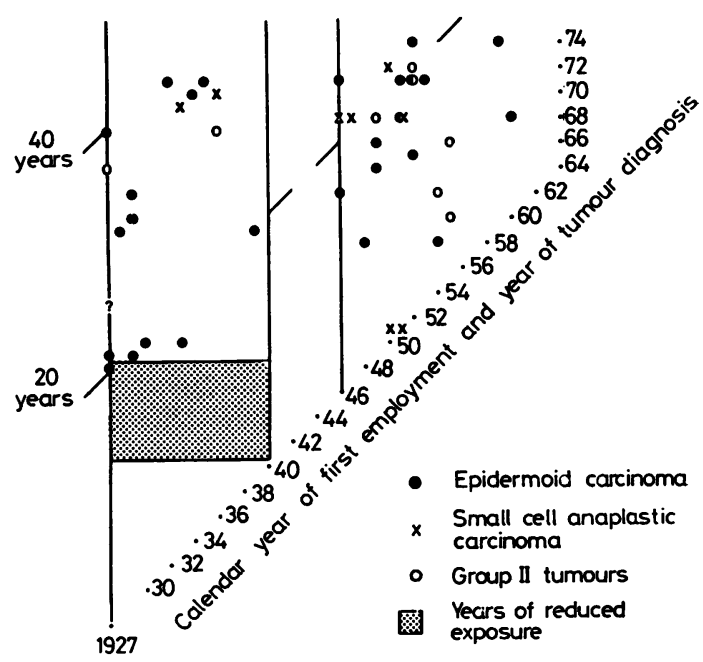

Fig. 3 The scatter of occurrence of lung tumours related to time of first employment at the nickel refinery (abscissa), and time of diagnosis of the tumour

(ordinate). For example, the epidermoid carcinoma indicated on the upper right-hand side of the diagram was diagnosed in 1974 in a person who started employment in 1959. Thus, tumours with a short development time will be close to the diagonal abscissa, whereas tumours taking a long time to develop will be situated far from this abscissa. The 20-and 40-year development stages are indicated on the left. 


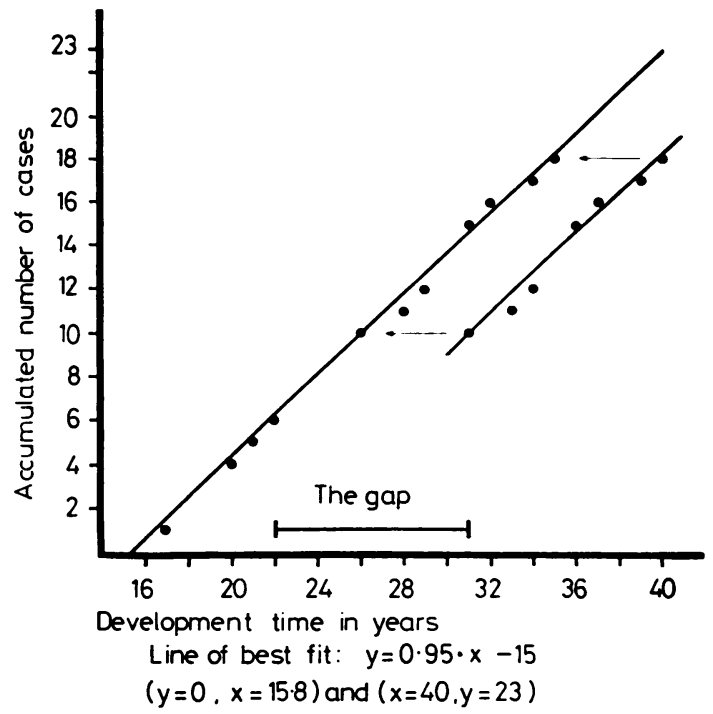

Fig. 4 Line of best fit for development time versus accumulated occurrence for lung tumours in workers employed in a nickel refinery. The slopes of the two lines are similar, and when the right part of the curve is moved five years to the left, one straight line results.

tive appearance of tumours will, if plotted against time, show an unbroken sigmoid curve. If weak carcinogens are used, few individuals develop tumours within the natural life span of the species, and then only the very first part of the curve will be reached (H. J. A. Kreyberg, 1965; Kreyberg, 1969), and that part is nearly linear.

In Fig. 4 the 18 cases of Series I have been plotted, and the earlier six and the later 12 cases, each separately, show nearly straight lines, with the same slopes. Thus, if the line for the later cases is moved five years to the left, it fuses with the line of the early cases. The two lines have been combined in the best possible way determined by the method of least squares. This finding greatly strengthens the assumption that the gap is a biological reality, caused by a period of reduced carcinogenic influences. Under the conditions which actually existed, the reduced carcinogenic influence may have been attributable to reduced exposure to the nickel factor and/or to another factor.

As regards exposure to the nickel factor, Table 1 shows that the first five lung tumours in this series developed, over the course of 17-22 years, in workers who started their employment in 1927-33. From the individual records we know that, with one exception (case No. 7), all worked continuously, including during the period of reduced activity.

The later 13 cases, occurring after the gap, are not randomly scattered; all but one appear after 31 or more years of development. They show a definite relationship to the year of first employment, with minor individual differences, and with a spread between 31 and 40 years. For these 13 cases the records show that in the six cases with shortest development time (mean 31.8 years) the workers were fully active until the tumour was diagnosed, with two exceptions, namely case No. 30 , with a small cell anaplastic carcinoma, with a break of employment from 1940-4, and case No. 42, a carcinoid tumour (Group II), with a period of latency of 20 years. With this latter case excepted, the mean employment time was 30 years.

Table 2 gives details of the six cases with the longest development time (mean $37 \cdot 3$ years) and shows that the cases with the longest development time in the whole of Series I are those connected with the lowest nickel exposure. In addition, in a single case (No. 14) there was a total employment time of only 14 years, a break in the years 1940-5, and a development time of 20 years (1939-59). In this series only a single case had a development time of less than 20 years (17 years).

Table 2 Series I workers with lung tumours taking the longest time to develop: periods of employment

\begin{tabular}{llll}
\hline Case no. & $\begin{array}{l}\text { Period(s) of } \\
\text { employment }\end{array}$ & $\begin{array}{l}\text { Total no. of years' } \\
\text { employment }\end{array}$ & $\begin{array}{l}\text { Latency time } \\
\text { (years) }\end{array}$ \\
\hline 3 & $1927-47$ & & \\
& $1957-62$ & 25 & 5 \\
10 & $1932-40$ & & 0 \\
12 & $1945-71$ & 34 & 24 \\
13 & $1934-40$ & & 26 \\
29 & $1945-46$ & 7 & 23 \\
35 & $1935-36$ & & 24 \\
\hline
\end{tabular}

\section{Series II}

These workers took up employment nearly 20 years later than those in Series I, which means that in Series II the longest observation time is about $\mathbf{3 0}$ years, against nearly 50 years in Series I, only the first period of which is therefore strictly comparable with Series I, as shown in Figs. 3 and 5. Nevertheless the Figures show considerable differences in development time between the two series. Whereas in Series I only one case had a development time of less than 20 years ( 17 years) out of 18 cases, there were no less than 17 such cases out of 24 (the two cases with a development time of one year and less are not included) in Series II. The mean development time for Group I tumours in Series I is 29.1 years (minimum 17 years, maximum 40 years). In Series II the 


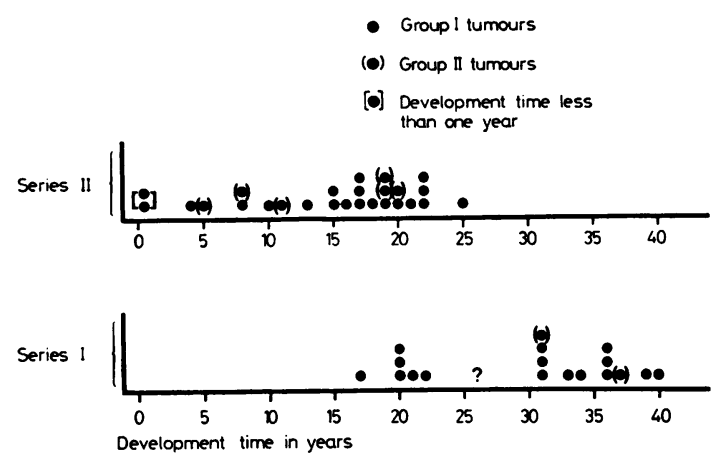

Fig. 5 Development time for lung tumours in Series I and Series II workers in a nickel refinery.

minimum development time is four years. No satisfactory valid mean or maximum time can obviously be given.

This difference between the two series cannot be explained simply by having missed the early cases of Series I, as already discussed. A few cases may have been missed, but certainly not as many as observed in Series II. Nor can they be fully explained by missing observations of the late cases of Series II. An explanation for the difference must, however, be sought.

Table 3 Age, on starting employment, of Series I and Series II workers exposed to nickel, who subsequently developed Group I tumours

\begin{tabular}{lllll}
\hline \multirow{2}{*}{$\begin{array}{llll}\text { Series } \\
\text { No. of } \\
\text { workers }\end{array}$} & \multicolumn{4}{l}{ Age on starting employment (years) } \\
\cline { 3 - 5 } & Mean & Minimum & Maximum \\
\hline I & 15 & $28 \cdot 6$ & 19 & 38 \\
II & 17 & $38 \cdot 3$ & 24 & 55 \\
\hline
\end{tabular}

The age of the workers when first employed is shown in Table 3. In spite of a considerable spread within each series, there are more older workers in Series II, some even entering service at an age close to the mean age of lung cancer recognition in the general population. This means that some workers could already have been in a preclinical stage of malignancy when they started their work at Falconbridge. The age of the workers at the time of diagnosis is shown in Table 4.

There is a remarkable similarity in the figures for the two series, in spite of the very great differences in development time, and furthermore the figures for both series correspond closely to the figures for the general population in the author's Norwegian control material. This indicates that nickel alone cannot be the sole carcinogen involved in this material. The obvious other factor to be considered is tobacco.
Table 4 Age of workers, exposed to nickel, at time of diagnosis of Group I tumours

\begin{tabular}{lllll}
\hline Series & No. of cases & \multicolumn{3}{l}{ Age in years } \\
\cline { 3 - 5 } & & Mean & Minimum & Maximum \\
\hline I & 15 & $57 \cdot 6$ & 40 & 75 \\
II & 17 & 56.0 & 44 & 73 \\
Kreyberg & & $58 \cdot 2$ & 31 & $75+$ \\
\hline
\end{tabular}

SMOKING IN THE FALCONBRIDGE LUNG CANCER CASES

In 1965 Dr G. Haaversen, the Factory Doctor, called our attention to the many heavy smokers among the workers with lung cancer. Although the amount of tobacco for sale during the war years was reduced in Norway, there was a rationing system available to all adults. It is well known that most people drew out all their rations because tobacco was a very valuable bartering commodity. Inveterate smokers could thereby obtain certain amounts of tobacco despite the general scarcity, and could possibly maintain a fairly high rate of smoking.

Table 5 Smoking and tumour incidence in workers at the Falconbridge nickel refinery

\begin{tabular}{lrl}
\hline Type of tumour & Smokers & Non-smokers \\
\hline Series I & & \\
$\quad$ Epidermoid carcinoma & 10 & $3(?)$ \\
Small cell anaplastic carcinoma & 2 & 0 \\
Group II tumour & 0 & 2 \\
Series II & 13 & 0 \\
Epidermoid carcinoma & 4 & 0 \\
Small cell anaplastic carcinoma & 3 & 2 \\
Adenocarcinoma & & \\
\hline
\end{tabular}

Among the 32 Group I tumour cases there were only three possible non-smokers (Table 5). These were the first three cases recorded and there is no contemporary documentation for them. On the other hand, four of seven Group II tumour patients were documented non-smokers. As the Group II tumours have only a weak relationship to tobacco smoking, such cases can therefore be used as controls of smoking. Admittedly seven cases are few, but a $3 / 4$ distribution of male smokers/non-smokers in the Agder Counties Area from which were recruited most of the Falconbridge workers at the relevant time, is a not unusual finding, according to our general knowledge of the local smoking habits.

Against this background, a proportion of at least $91.9 \%$ of smokers among the Group I tumour cases is much more than would be expected if these tumours were unrelated to smoking, and here the number is large enough to be of significance. This means that a considerable number of Group I 
tumour cases were also exposed to tobacco carcinogens in addition to the nickel. As most of the smokers started smoking tobacco years before their exposure to nickel, the latter factor will in time be secondary to the tobacco. The full significance of this observation can, at present, only be guessed, but it cannot be ignored. Kreyberg (1969) found only six non-smokers among 473 cases of epidermoid carcinoma, and only one of the six had been in contact with metal work. Furthermore, out of 123 men with small cell anaplastic carcinoma there was only one non-smoker.

The evidence presented indicates that tobacco smoking is an important additional factor in lung cancer in nickel workers. As a consequence neither factor can be ignored when the development time is evaluated.

Development time, as the term has been defined and used solely with regard to nickel, has not proved useful. The conditions in the two series present a most confusing and inconsistent picture. An alternative hypothesis may be tested in which development time is defined as from the moment of starting smoking instead of the moment of first employment in the refinery. In Norway most smokers start their smoking between 14 and 18 years of age, a comparatively short span of time, if compared to the wide range in age connected with the first employment at the nickel refinery. With this approach, the similar mean age at diagnosis can be satisfactorily explained. The development time of lung cancer due to nickel alone is accordingly obscured.

The minimum development time will be defined as the shortest possible period from the exposure to a carcinogen until the diagnosis of the tumour. That is a theoretical time. What actually is observed is the shortest time in each set of observations. In our numerous control subjects the shortest development time observed for epidermoid carcinoma related to tobacco smoking alone and embracing all trades and occupations was 3 cases out of 473 , and with development times of 17, 18 and 19 years. In our present Series I, the shortest development time for the same tumour type related to nickel alone was likewise 17 years in a possible non-smoker. In our control subjects, among those with small cell anaplastic carcinomas there were 2 cases out of 123 with a development time of 13 years in smokers.

Sunderman (1973) in a review paper refers to a development time in nickel workers as short as 13 years, however without considering a possible tobacco factor in addition. Šikl (1938) discussing the very potent lung carcinogen at Jachymov where three out of four workers developed lung cancer noted that 'le plus court laps de temps ayant suffi a provoquer le cancer était 13 ans.'
Jablon and Kato (1971) studied the long-term effects of the atomic bombing of Hiroshima and Nagasaki and found for the period 1955-70 a lung cancer incidence for certain groups 1.4 times higher than the normal, estimated 16-25 years after exposure. The tumours were Group I types. There is no information on smoking. Court Brown and Doll (1965), on the other hand, detected lung cancer as early as six years after the start of treatment in patients treated for ankylosing spondylitis with radiotherapy, involving the chest, with an increased risk of 1.8 times normal of developing lung cancer (types not stated). This is very similar to some cases of our Series II, with the diagnosis of epidermoid carcinoma 4, 8 and 10 years after taking up employment in the refinery. It would therefore be interesting to have the mean age at diagnosis also of the spondylitis cases with lung cancer, as well as information on smoking.

This means that the true development time for cancer can be rationally studied only when one single carcinogen is concerned. In the study of industrial as well as in iatrogenic cancer, tobacco should not be ignored. The incidence may be increased when weak carcinogens are involved without the mean age at diagnosis being markedly altered, as mentioned above.

THE MAGNITUDE OF THE NICKEL FACTOR IN INDUSTRIAL LUNG CANCER

Doll (1958) concluded from a study of British cases that during 1948-56 the risk to nickel workers of dying from the disease was approximately five times 'normal', and Pedersen et al. (1973) in their study of the Falconbridge cases found that the highest risk was among the men involved in roasting, smelting and electrolysis. For these men the ratio of observed to expected cases of lung cancer was 7:1.

Normality in relation to a morbid condition should logically be non-existent. What is 'normal' or 'to be expected' is obviously a variable, dependent upon geographical location (country or region) and upon time.

As most lung cancer patients die from their disease, the mortality statistics may serve as a close indicator of the 'normal', as regards lung cancer. The mortality rates for Norway in the period under study (Table 6), show that what is 'normal' or 'expected' as regards lung cancer in Norway, has increased 25 times in the towns and 10 times in the rural districts in the course of 40 years. The main cause of this change is tobacco smoking. In this connection it may be of interest to recall that Kreyberg (1969), reporting 551 Group I tumours from 1950-64, in the age groups 35-69 years found the risk of developing lung cancer of these types to be 
Table 6 The yearly lung cancer mortality rate per 100000 males in Norway

\begin{tabular}{lcc}
\hline Period & Urban areas & Rural areas \\
\hline Mid-1930s & 2 & 2 \\
Mid-1950s & 25 & 5 \\
Mid-1970s & 50 & 20 \\
\hline
\end{tabular}

23.8 times higher in smokers than in non-smokers, a figure of the same order of magnitude as that of the total increase in the general population during $\mathbf{4 0}$ years.

If a nickel refinery in a town in Norway in the year 1935 produced a single case of lung cancer by nickel alone, and the local conditions remained unchanged, a single case a year would also be produced in 1975. However, if the lung cancer frequency in the refinery increased in proportion to the frequency in the population at large, 25 new cases could be expected, and 24 of these would be caused and/or influenced by the ambient factors (mainly tobacco smoking), and not by the nickel per se. This means that the true risk to a healthy person of developing lung cancer as a nickel worker can only be measured in a population of non-smokers.

\section{TUMOUR TYPES IN THE FALCONBRIDGE CASES}

Among the employees not exposed to nickel there were two cases of tumour, one each of Group I and Group II, as mentioned above. Among the workers exposed to nickel, 32 Group I tumours and 7 Group II tumours were registered, giving a ratio of $4 \cdot 6 / 1$. Table 7 shows the ratio between Group I and Group II tumours in Kreyberg's material from 1969, with regard to different occupations. The bottom line shows the corresponding ratios for lung tumours at the Falconbridge nickel refinery.

Table 7 The ratio of Group I: Group II tumours in various studies

\begin{tabular}{llc}
\hline Subjects and source & Ratio & No. of cases \\
\hline Kreyberg (1969) & & \\
Farmers and smallholders & $0 \cdot 9 / 1$ & $18 / 19$ \\
Commercial and office workers & $4 \cdot 0 / 1$ & $88 / 22$ \\
Doctors, dentists, lawyers, engineers & $4 \cdot 6 / 1$ & $23 / 5$ \\
Metal workers & $5 \cdot 8 / 1$ & $87 / 15$ \\
Carpenters, masons, painters & $6 \cdot 4 / 1$ & $32 / 5$ \\
Total & $3 \cdot 6 / 1$ & $596 / 167$ \\
Falcon-bridge; nickel-exposed & $4 \cdot 6 / 1$ & $32 / 7$ \\
\hline
\end{tabular}

In our previous studies a high Group I/Group II tumour ratio has been regarded as an indicator of a high lung cancer risk, on the assumption that Group II tumours are little, if at all, influenced by the carcinogen in question. If this assumption holds good for nickel also and the number of cases is representative, the nickel lung cancer risk is higher than the risk in the general population, as shown by other authors. If, on the other hand, the development of adenocarcinomas is also enhanced by exposure to nickel and/or the number of cases is not representative, the observed ratio is not meaningful. Only further studies can give a significant answer to this specific question. For valid comparative studies the same histological definitions are necessary.

The author wishes to thank the Director of the Norwegian Cancer Registry, Dr Einar Pedersen and his colleagues for permission to use their material and for many useful discussions, and Research Engineer Dr Rolf Bjerknes for his assistance in calculating the data of Figure 4.

\section{References}

Court Brown, W. M., and Doll, R. (1965). Mortality from cancer and other causes after radiotherapy for ankylosing spondylitis. British Medical Journal, 2, 1327-1332.

Doll, R. (1958). Cancer of the lung and nose in nickel workers. British Journal of Industrial Medicine, 15, 217-223.

Doll, R. (1964). Mortality in relation to smoking: Ten years' observations of British doctors. British Medical Journal, 1, 1399-1410; 1640-1667.

Jablon, S., and Kato, H. (1971). Radiation dose and mortality of A-bomb survivors, 1950-1971. Life Span Study Report No. 6. Atomic Bomb Casualty Commission Technical Report 10-71; Hiroshima.

Kreyberg, H. J. A. (1965). Empirical relationship of lung cancer incidence to cigarette smoking and a stochastic model for the mode of action of carcinogens. Biometrics, 21, 839-857.

Kreyberg, L. (1954a). The significance of histological typing in the study of the epidemiology of primary epithelial lung tumours: A study of 466 cases. British Journal of Cancer, 8, 199-208.

Kreyberg, L. (1954b). Occupational influences in a Norwegian material of 235 cases of primary epithelial lung tumours. British Journal of Cancer, 8, 605-612.

Kreyberg, L. (1962). Histological Lung Cancer Types. Norwegian Universities Press: Oslo.

Kreyberg, L. (1969). Aetiology of Lung Cancer. Universitetsforlaget: Oslo.

Løken, A. C. (1950). Lungecarcinom hos nikkelarbeidere. Tidsskrift forDen norske lageforening (Norw.), 70, 376-378.

Pedersen, E., Høgetveit, A. C., and Andersen, A. (1973). Cancer of respiratory organs among workers at a nickel refinery in Norway. International Journal of Cancer, 12, 32-41.

Sikl, H. (1938). Le cancer pulmonaire chez les mineurs. $\mathrm{La}$ Presse Médicale, 1, 673-674.

Sunderman, F. W., Jr. (1973). The current status of nickel carcinogenesis. Annals of Clinical Laboratory Science, 3, 156-180. 